ORIGINAL ARTICLE

\title{
Health status as a potential effect modifier of the relation between noise annoyance and incidence of ischaemic heart disease
}

\author{
W Babisch, H Ising, J E J Gallacher
}

Occup Environ Med 2003;60:739-745

See end of article for authors' affiliations

Correspondence to: Dr W Babisch, Federal Environmental Agency, PO Box 330022,14191 Berlin, Germany; wolfgang.babisch@uba.de

Accepted

7 November 2002
Aims: Traffic noise is a psychosocial stressor. Epidemiological studies suggest chronic noise stress to be a risk factor for cardiovascular disorders.

Methods: In a prospective cohort study, the association between annoyance and disturbances due to road traffic noise and the incidence of ischaemic heart disease (IHD) was studied in 3950 middle aged men. Results: Depending on the questionnaire item, non-significant odds ratios for IHD incidence ranging from 0.9 to 1.4 were found for the highly noise annoyed/disturbed subjects when compared with the less annoyed/disturbed subjects, over the six year follow up period. However, this relation was strongly modified by the prevalence of pre-existing chronic diseases. In subjects free of any chronic disease at the beginning of the follow up, significant odds ratios between 1.7 and 3.0 were seen. In the subgroup with chronic diseases no such noise effects were seen. This surprising result of no effect in the group of people with a potential risk, due to pre-existing health problems, may be because of the dilution of the true effect due to recall bias.

Conclusions: Annoyance and disturbance due to road traffic noise is associated with a higher incidence of IHD. Prevalence of disease can be an important effect modifier of the relation between noise annoyance and health outcomes.
$\mathrm{T}$ raffic noise causes considerable disturbance and annoyance in exposed subjects. ${ }^{12}$ Besides the psychosocial effects of community noise, there is concern about the impact of noise on public health, particularly regarding cardiovascular outcomes. ${ }^{3}$ Non-auditory health effects of noise have been studied in humans for a couple of decades using laboratory and empirical methods.$^{5-7}$ Biological reaction models have been derived which are based on the general stress concept. ${ }^{8-10}$

Test persons who are exposed to high noise levels have shown decreases in electrical skin resistance, skin temperature, and blood flow in peripheral blood vessels due to vasoconstriction, and increases in blood pressure and heart rate, indicating an arousal of the autonomic nervous system and the endocrine system. ${ }^{11-16}$ In contrast to the acute noise effects observed at higher-namely occupational-noise levels, physiological effects from relatively low environmental noise levels primarily occur when the sound level disturbs cognitive functions, causes emotional reactions, or interferes with activities of the individual such as mental tasks, relaxation, or sleep. ${ }^{77-20}$

According to the general stress model, activation of the sympathetic and the endocrine systems (stress indicators) is associated with changes in physiological functions and metabolism, including blood pressure, cardiac output, blood lipids, glucose, blood clotting factors, and other functions. ${ }^{21-23}$

\section{Main messages}

- Noise annoyance due to exposure to road traffic may be a risk factor for the incidence of ischaemic heart disease. The prevalence of pre-existing chronic diseases modifies this association.
Since many of these factors are known to be classical cardiovascular risk factors, the hypothesis has emerged that chronic noise exposure causes permanent changes in these risk factors (due to dysregulation) and thus increases the risk of cardiovascular disease-in particular, hypertension and ischaemic heart disease. ${ }^{24}{ }^{25}$ Although the noise hypothesis is now well established, ${ }^{46}$ and large scale epidemiological studies have been carried out for a long time, ${ }^{27}{ }^{28}$ the epidemiological evidence of the long term effects of environmental noise on health is still inconclusive or limited. ${ }^{3} 72629$ However, some studies suggest that transportation noise is associated with adverse cardiovascular effects, in particular ischaemic heart disease.

The Caerphilly and Speedwell studies are two closely linked cohort studies in which the effects of a number of potential risk factors, including road traffic noise, on the prevalence and incidence of ischaemic heart disease (IHD) were investigated..$^{30-36}$ Cross sectional and longitudinal results regarding exposure of the subjects to objective noise measures-namely the average A-weighted sound pressure level-have been given previously. ${ }^{37}$ The present paper focuses on the subjective dimensions of the perception of sound-namely disturbances and annoyance-and its impact on cardiovascular risk. According to the noise stress model, subjective noise measures may be more closely related to the health outcome than the objective sound level when considering the potential effect chain. The effect chain is: sound $>$ disturbance/annoyance $>$ stress indicators (for

\section{Policy implications}

- Chronic environmental noise stress increases the risk of ischaemic heart disease. 
example, stress hormones) $>$ biological risk factors (for example, blood pressure, blood lipids) $>$ disease (for example, myocardial infarction). ${ }^{38}$

\section{METHODS}

Two cohorts of 2512 (Caerphilly, South Wales) and 2348 (Speedwell, England) middle aged men in the United Kingdom were recruited to study the predictive power of already known and new risk factors for IHD. In both studies, investigators followed identical protocols with respect to noise, medical, sociodemographic, and biochemical measurements, and statistical data analyses. The response rates for phase 1 were $89 \%$ (Caerphilly) and 92\% (Speedwell), which were extremely high and gave little concern about selection bias. The first follow up investigations (phase 2) were conducted after approximately four years. The second follow up investigations (phase 3) were conducted after approximately 10 years. Inasmuch as a detailed noise questionnaire was first administered during the second phase of the study, the follow up analyses presented here refer to the reconstructed cohorts of phase 2 and the observation period from phase 2 to phase 3 .

The reconstructed cohort of phase 2 of the Caerphilly sample consisted of 1951 men of the original cohort who were seen again at the clinic (5.3\% had died), plus 447 men of the same age range who had moved into the area since the original cohort was identified. Altogether these were 2398 men, aged 47-67 years. The Speedwell reconstructed cohort consisted of the 2055 men of the original cohort who were seen again at the phase 2 clinics $(4.5 \%$ had died), aged $48-$ 66 years. No new subjects were recruited in Speedwell. The statistical noise analyses were carried out on a pooled sample of 3997 men aged 47-67 years, who had filled in the noise questionnaire during phase 2 . The average follow up interval for these men was 67 months (SD 6 months).

Long term and short term noise measurements were carried out in the streets where subjects lived and noise maps of the areas were established. The subjects were grouped according to $5 \mathrm{~dB}(\mathrm{~A})$ categories of the outdoor Aweighted average sound pressure level, from 6 to 22 hours $\left(L_{\text {eq }} 6-22 \mathrm{~h}\right)$. Because of the high correlation between day and night noise levels in the communities (correlation coefficient $r=0.94$, mean difference $8 \mathrm{~dB}(\mathrm{~A})$ ), this noise level is used as an indicator for the overall traffic noise exposure of the streets in the study. In personal interviews annoyance and disturbance of traffic noise at home were assessed on a five grade scale (never, seldom, sometimes, often, always). The questionnaire items referred to annoyance (global item), disturbance of concentration, conversation, or listening to radio/TV and relaxation, being nervous or tense, disturbance in going to sleep, and waking up at night. ${ }^{39}$ The construction of the noise questionnaire was closely related to the recommendations given in the literature..$^{40-42}$

The incidence of ischaemic heart disease was defined when a major IHD event occurred between the follow up phases. These events could either be IHD death (coded ICD 410-414 on death certificate), definite clinical non-fatal myocardial infarction (MI) meeting the WHO criteria regarding clinical history, electrocardiogram (ECG) and enzyme changes (via written documentation in hospital or general practitioner records), or ECG defined MI that met WHO criteria (major (1-1-any), or selected moderate (1-2-1 to $1-2-5$, or $1-2-7)$ Q waves when there were no Q waves (1-1-any, 1-2-any, or $1-$ 3-any) for the reference phase, and no left bundle branch block (7-1) on any ECG prior to the qualifying ECG). ${ }^{43}$

All statistical analyses on the relation between traffic noise and IHD incidence were controlled (model adjusted) for potential confounding factors-that is, age, social class, marital status, smoking, body mass index, family history of myocardial infarction, employment status, subjective noise sensitivity based on a single item, cohort (Caerphilly or Speedwell), prevalence of IHD (clinically assessed by ECG (Minnesota coding) or chest pain interview), and the self reported lifetime prevalence of illnesses including chronic diseases (general health interview). The latter included heart attack or coronary thrombosis, stroke, yellow jaundice or liver disease, kidney disease, gout, thyroid problems, high blood pressure, blood clots or phlebitis (inflammation in the legs), and diabetes. A new variable-pre-existing disease-was defined which was coded " 1 " when either prevalence of IHD or lifetime prevalence of any of the chronic diseases during phase 2 was true. Coding " 0 " referred to a strictly "disease free" group of subjects where prevalent diseases could not confound the association between noise annoyance and IHD incidence. Different mechanisms could be considered about how pre-existing disease could affect the relation between noise and IHD incidence. One is that pre-existing disease could cause psychological strain that affects the subjective ratings of noise of the individuals. Another is that preexisting disease may be an additional stressor that could increase the physiological sensitivity of the individuals towards other stressors such as noise (see the discussion).

With regard to possible effect modification of pre-existing disease-the primary issue of this article-the analyses on the relation between noise and IHD incidence were stratified according to the presence of pre-existing disease. Separate analyses were carried out for subjects with and without disease prevalence (separate models). Relative risks are given with reference to the lowest noise exposure category in each subgroup (odds ratio l).

The multiple logistic regression technique (SPSS 9.0) was applied to calculate estimates of the relative risk (odds ratio) and the $95 \%$ confidence intervals, and to control for confounding factors, based on cumulative incidence cases during the follow up period. No person-years were assessed, because the actual occurrence of the event during the six years follow up was unknown.

\section{RESULTS}

Death certificates were available for all men who died before the final examination occurred, with the exception of one from the Caerphilly cohort and two from the Speedwell cohort. In Caerphilly $94 \%$ and in Speedwell $87 \%$ of the 10 year follow up survivors were seen at the clinic again. In addition, $2 \%$ and $3 \%$, respectively, had postal cardiovascular questionnaires after hospital admission for chest pain, and records from all local hospitals were then searched for the clinical diagnoses. The six year cumulative incidence of major IHD was 161 (of 2398) and 191 (of 2055) subjects in the Caerphilly and Speedwell cohorts, respectively. The average annual incidence rate was $1.38 \%$ for both cohorts. A total of 3997 men filled in the noise questionnaire (90\%). Due to missing values, adjusted analyses in the study refer to the pooled sample of 3950 men for whom complete information on all the considered variables was given. The average age of the men in the pooled sample was 57.3 years (SD 4.5).

Table 1 shows the odds ratios of the relation between control variables and IHD incidence. The results are given for the total sample and the subsamples of subjects with and without pre-existing disease, prior to follow up. The following factors were significantly associated with IHD risk: smoking, family history of IHD, age, body mass index, unemployment, area, IHD prevalence, and pre-existing disease. These effects are very similar in men with and without pre-existing disease.

Table 2 gives the percentages of men in each disturbance/ annoyance category for each questionnaire item. Depending on the item, between $3 \%$ and $4 \%$ of the men were highly 
Table 1 Association between control variables and IHD incidence; pooled sample, six year follow up

\begin{tabular}{|c|c|c|c|}
\hline \multirow[b]{2}{*}{ Control variable } & \multicolumn{3}{|l|}{ Odds ratio $(95 \% \mathrm{Cl})$} \\
\hline & Total sample $(n=3950)$ & $-P D(n=2431)$ & $+P D(n=1519)$ \\
\hline Social class (manual $v$ partly skilled or unskilled) & $1.1(0.7$ to 1.4$)$ & $1.0(0.6$ to 1.6$)$ & $1.0(0.6$ to 1.6$)$ \\
\hline $\begin{array}{l}\text { Social class (non-manual } v \text { partly skilled } \\
\text { or unskilled) }\end{array}$ & $1.2(0.8$ to 1.7$)$ & $0.9(0.5$ to 1.6$)$ & $1.4(0.8$ to 2.3$)$ \\
\hline $\begin{array}{l}\text { Social class (professional or intermediate } v \text { partly } \\
\text { skilled or unskilled) }\end{array}$ & $1.1(0.8$ to 1.4$)$ & $1.0(0.7$ to 1.8$)$ & $0.9(0.6$ to 1.5$)$ \\
\hline Employment status (employed $v$ unemployed) & $0.7(0.5$ to 0.9$)$ & $0.6(0.4$ to 0.8$)$ & $0.8(0.5$ to 1.1$)$ \\
\hline Smoking (ex-smoker $v$ non-smoker) & $1.4(1.0$ to 2.2$)$ & $1.5(0.8$ to 2.8$)$ & $1.5(0.9$ to 2.6$)$ \\
\hline Smoking (current smoker $v$ non-smoker) & $2.1(1.5$ to 3.3$)$ & 2.7 (1.4 to 4.9$)$ & $1.8(1.1$ to 3.2$)$ \\
\hline Family history of IHD & 1.5 (1.1 to 2.0$)$ & $1.5(1.0$ to 2.3$)$ & $1.5(1.0$ to 2.2$)$ \\
\hline $\begin{array}{l}\text { Prevalence of pre-existing diseases (summation } \\
\text { of the following two items) }\end{array}$ & $2.0(1.6$ to 2.6$)$ & - & - \\
\hline IHD prevalence & $2.1(1.6$ to 2.6$)$ & - & - \\
\hline Lifetime prevalence chronic diseases & $1.7(1.3$ to 2.1$)$ & - & - \\
\hline Area (Speedwell $v$ Caerphilly) & 1.6 (1.3 to 2.2$)$ & 1.5 (1.0 to 2.2$)$ & $1.9(1.3$ to 2.7$)$ \\
\hline Age (per year) & 1.05 (1.02 to 1.08$)$ & $1.06(1.01$ to 1.11$)$ & 1.04 (1.00 to 1.09$)$ \\
\hline Body mass index $\left(\right.$ per $\left.\mathrm{kg} / \mathrm{m}^{2}\right)$ & 1.06 (1.02 to 1.09$)$ & 1.05 (1.00 to 1.10$)$ & $1.07(1.02$ to 1.11$)$ \\
\hline $\begin{array}{l}\text { Subjective noise sensitivity (much or very } \\
\text { much } v \text { not at all, a little, or moderate) }\end{array}$ & $0.9(0.6$ to 1.3$)$ & $1.1(0.6$ to 1.9$)$ & $0.8(0.5$ to 1.3$)$ \\
\hline
\end{tabular}

annoyed/disturbed by traffic noise (categories $4+5=$ "often" + "always") and a further 10-20\% were moderately annoyed/disturbed by traffic noise (category $3=$ "sometimes") annoyed/disturbed by traffic noise.

Table 3 gives the prevalence of pre-existing disease in each objective (sound level) and subjective (annoyance/disturbance) exposure category. Regarding the sound level, no associations between the outdoor traffic noise level and disease prevalence can be seen. However, regarding annoyance/disturbance ratings, significant trends towards higher prevalences in higher annoyed/disturbed subjects were found.

Table 4 gives the percentages of highly annoyed/disturbed subjects according to traffic noise level for the total sample and the two strata of subjects with and without pre-existing disease. The proportion of highly annoyed men increases with higher traffic noise in both strata. Men with pre-existing disease, however, reported greater annoyance to traffic noise level than men without, at lower sound levels. Regarding disturbances similar associations can be seen, which are not always significant. However, men with pre-existing disease tend to be more disturbed.

Table 5 gives odds ratios of IHD incidence in different objectively (sound pressure level) and subjectively (disturbances, annoyance) traffic noise exposed groups of subjects, which are model adjusted for the set of control variables. The results are given for the total sample and the two stratified samples of subjects with and without pre-existing disease (separate models). No significant effects of sound exposure (traffic noise level) on incident IHD were found.

Regarding subjective assessment of noise, for the sample as a whole, no effect of annoyance/disturbance on incident IHD was found. The odds ratios ranged between 0.9 and 1.4, but they all had 95\% confidence intervals straddling the value 1 . Thus, the association of IHD incidence with subjective categories of noise exposure does not tend to be any closer than with the objective assessment of exposure (traffic noise level) where non-significant relative risks range between 1.1 and 1.3 in the highest noise category, compared with the lowest noise category.

The stratified analyses, however, clearly show the presence of effect modification (interaction). In subjects with no preexisting disease, those highly disturbed/annoyed showed higher relative risks of IHD incidence than those never annoyed/disturbed with odds ratios ranging between 1.7 and 3.0, which is significant for most items. By way of contrast, in subjects with pre-existing disease, no association between annoyance/disturbance due to traffic noise and IHD incidence was found.

Regarding the objective traffic noise level, an opposite nonsignificant tendency of effect modification was found. While there was no higher IHD risk in noise exposed subjects without pre-existing disease, a borderline effect was found in subjects with pre-existing disease for the contrast between the highest and lowest noise categories $(\mathrm{RR}=1.8$, $\mathrm{p}<0.10)$. This is contrary to what we have found using the subjective exposure ratings. The outdoor noise level was adjusted for room orientation and window opening habits. $^{3744}$

\section{DISCUSSION}

The identification of potential effect modifiers of the relation between noise and health has become a major issue of modern epidemiological noise research. ${ }^{26}{ }^{45}$ Considerable

Table 2 Distribution of subjective responses to traffic noise using the questionnaire categories

\begin{tabular}{|c|c|c|c|c|c|}
\hline \multirow[b]{2}{*}{ Item (noise effect) } & \multicolumn{5}{|l|}{ Category } \\
\hline & 1 (never) & 2 (seldom) & 3 (sometimes) & 4 (often) & 5 (always) \\
\hline Annoyance & $51.9 \%$ & $24.7 \%$ & $19.5 \%$ & $2.7 \%$ & $1.2 \%$ \\
\hline Disturbed concentration & $46.7 \%$ & $29.1 \%$ & $19.8 \%$ & $2.9 \%$ & $1.5 \%$ \\
\hline Disturbed conversation, radio, TV & $58.2 \%$ & $23.2 \%$ & $14.8 \%$ & $2.8 \%$ & $1.0 \%$ \\
\hline Disturbed relaxation & $59.1 \%$ & $24.0 \%$ & $13.6 \%$ & $2.3 \%$ & $1.0 \%$ \\
\hline Feeling nervous or tense & $68.4 \%$ & $18.8 \%$ & $10.2 \%$ & $1.9 \%$ & $0.7 \%$ \\
\hline Difficulty in falling asleep & $66.9 \%$ & $18.3 \%$ & $11.6 \%$ & $2.3 \%$ & $0.9 \%$ \\
\hline Waking up at night & $51.5 \%$ & $24.8 \%$ & $19.7 \%$ & $2.9 \%$ & $1.1 \%$ \\
\hline
\end{tabular}


Table 3 Prevalence of pre-existing diseases in different traffic noise exposed subjects

\begin{tabular}{|c|c|c|c|c|c|c|}
\hline \multirow{3}{*}{$\begin{array}{l}\text { Exposure variable } \\
\text { Traffic noise level (dB(A)) }\end{array}$} & \multicolumn{4}{|c|}{ Exposure category } & \multicolumn{2}{|l|}{$\chi^{2}$ test } \\
\hline & 1 & 2 & 3 & 4 & \multirow[b]{2}{*}{ Group } & \multirow[b]{2}{*}{ Trend } \\
\hline & $51-55$ & $56-60$ & $61-65$ & $66-70$ & & \\
\hline Traffic noise level & $38.3 \%$ & $37.0 \%$ & $41.4 \%$ & $37.7 \%$ & 0.561 & 0.622 \\
\hline Adjusted traffic noise level* & $38.7 \%$ & $37.3 \%$ & $38.2 \%$ & $36.4 \%$ & 0.905 & 0.518 \\
\hline Annoyance/disturbance & Never & Seldom & Sometimes & Often+always & & \\
\hline Annoyance & $37.3 \%$ & $37.1 \%$ & $40.5 \%$ & $52.3 \%$ & 0.001 & 0.003 \\
\hline Concentration & $37.5 \%$ & $35.5 \%$ & $41.5 \%$ & $54.9 \%$ & 0.000 & 0.000 \\
\hline Conversation & $37.0 \%$ & $37.6 \%$ & $42.6 \%$ & $49.0 \%$ & 0.003 & 0.001 \\
\hline Relaxation & $37.0 \%$ & $37.4 \%$ & $43.4 \%$ & $52.7 \%$ & 0.000 & 0.000 \\
\hline Nervous or tense & $36.4 \%$ & $43.0 \%$ & $40.0 \%$ & $54.4 \%$ & 0.000 & 0.000 \\
\hline Falling asleep & $37.3 \%$ & $37.2 \%$ & $44.1 \%$ & $49.6 \%$ & 0.002 & 0.001 \\
\hline Waking up & $37.0 \%$ & $35.8 \%$ & $44.1 \%$ & $46.2 \%$ & 0.000 & 0.000 \\
\hline
\end{tabular}

research has been carried out on the relation between sound level and noise annoyance including modifying factors. ${ }^{10} 47$ Annoyance is understood as a mediator in the relation between sound and somatic health. However, little information is available on the relation between noise annoyance and health. ${ }^{27}$ Studies suggest that the relation between self reported subjective health and psychological factors interacts with the prevalence of chronic conditions and the subjects' disabilities. ${ }^{48}{ }^{49}$ Studies on work stress showed that subjective appraisal of stressors by persons with increased blood pressure may be an invalid measure of objectively verifiable stressors..$^{50}$ The "response bias model" and the "adaption level theory" were used to explain differences in reported annoyance under steady state conditions except for changing noise conditions. ${ }^{51}{ }^{52}$ According to these concepts, individual minimum and maximum points on an annoyance scale may be dependent on the level of noise exposure itself and one's optimal level of stimulation. The latter differs from one person to another as a matter of experience and the individual's ability and costs to adapt. Non-noise factors, such as physical health, may affect the individual's expectation level and response scale.
The results of this prospective study on the impact of road traffic noise on the incidence of IHD gave only marginal support to the hypothesis that subjects with health problems may be a risk group for adverse health effects of environmental noise, ${ }^{26} 53$ when the objective sound level is considered. Higher odds ratios in higher noise (sound) exposed subjects were only seen in the subgroup of subjects with preexisting diseases, if at all. A simple explanation is that these people have less reserve to cope with the additional noise stress. Another explanation is that the noise further increases psychophysiological arousal, which may be already higher in these people with health problems. In noise regulations, ill people (hospital areas) are often considered as a potential risk group for higher susceptibility towards noise stress. ${ }^{54}$

As far as ratings of annoyance/disturbance are concerned, subjects with pre-existing disease in the present study were more often highly annoyed/disturbed by traffic noise than subjects without such health problems, even for low sound exposure levels (table 4). Conceptually, pre-existing disease acted as a moderator of the relation between sound and annoyance. Furthermore, pre-existing disease acted as an effect modifier on this relation. Positive trends of increasing

\begin{tabular}{|c|c|c|c|c|c|c|}
\hline \multirow[b]{2}{*}{ Item (categories $4+5$ ) } & \multicolumn{4}{|c|}{ Traffic noise level $(\mathrm{d} B(\mathrm{~A}))$} & \multicolumn{2}{|l|}{$\chi^{2}$ test } \\
\hline & $51-55$ & $56-60$ & $61-65$ & $66-70$ & Group & Trend \\
\hline Annoyance & $2.1 \%$ & $6.1 \%$ & $8.8 \%$ & $10.3 \%$ & 0.000 & 0.000 \\
\hline -PD & $1.7 \%$ & $4.6 \%$ & $5.3 \%$ & $10.1 \%$ & 0.000 & 0.000 \\
\hline$+\mathrm{PD}$ & $2.8 \%$ & $8.6 \%$ & $13.9 \%$ & $10.5 \%$ & 0.000 & 0.000 \\
\hline Concentration & $4.2 \%$ & $4.2 \%$ & $5.3 \%$ & $5.0 \%$ & 0.694 & 0.290 \\
\hline$-P D$ & $3.0 \%$ & $3.8 \%$ & $3.8 \%$ & $3.2 \%$ & 0.880 & 0.611 \\
\hline$+\mathrm{PD}$ & $6.0 \%$ & $5.0 \%$ & $7.5 \%$ & $7.9 \%$ & 0.688 & 0.356 \\
\hline Conversation, radio, TV & $3.3 \%$ & $3.7 \%$ & $7.1 \%$ & $5.0 \%$ & 0.001 & 0.001 \\
\hline$-P D$ & $2.8 \%$ & $3.4 \%$ & $5.7 \%$ & $3.7 \%$ & 0.092 & 0.052 \\
\hline$+P D$ & $4.1 \%$ & $4.3 \%$ & $9.1 \%$ & $7.0 \%$ & 0.021 & 0.008 \\
\hline Relaxation & $3.0 \%$ & $2.6 \%$ & $3.5 \%$ & $6.0 \%$ & 0.045 & 0.023 \\
\hline$-P D$ & $2.6 \%$ & $1.7 \%$ & $2.6 \%$ & $2.1 \%$ & 0.819 & 0.645 \\
\hline$+\mathrm{PD}$ & $3.6 \%$ & $4.3 \%$ & $4.8 \%$ & $12.3 \%$ & 0.000 & 0.000 \\
\hline Nervous or tense & $2.4 \%$ & $2.6 \%$ & $2.9 \%$ & $3.6 \%$ & 0.640 & 0.217 \\
\hline$-P D$ & $1.8 \%$ & $2.1 \%$ & $2.6 \%$ & $1.6 \%$ & 0.818 & 0.731 \\
\hline$+\mathrm{PD}$ & $3.4 \%$ & $3.6 \%$ & $3.2 \%$ & $7.0 \%$ & 0.274 & 0.186 \\
\hline Falling asleep & $2.9 \%$ & $2.6 \%$ & $4.4 \%$ & $4.6 \%$ & 0.134 & 0.032 \\
\hline$-P D$ & $2.6 \%$ & $1.7 \%$ & $3.4 \%$ & $2.7 \%$ & 0.690 & 0.743 \\
\hline$+P D$ & $3.3 \%$ & $4.3 \%$ & $5.9 \%$ & $7.9 \%$ & 0.063 & 0.007 \\
\hline Waking up & $3.4 \%$ & $4.5 \%$ & $5.1 \%$ & $6.3 \%$ & 0.044 & 0.005 \\
\hline$-P D$ & $3.3 \%$ & $2.5 \%$ & $5.3 \%$ & $3.7 \%$ & 0.323 & 0.301 \\
\hline$+\mathrm{PD}$ & $3.7 \%$ & $7.9 \%$ & $4.8 \%$ & $10.5 \%$ & 0.003 & 0.002 \\
\hline
\end{tabular}


Table 5 Model adjusted odds ratios of IHD incidence for different traffic noise exposed groups of subjects (odds ratio, $95 \% \mathrm{Cl}$ )

\begin{tabular}{|c|c|c|c|c|}
\hline \multirow[t]{2}{*}{ Exposure variable } & \multicolumn{4}{|c|}{ Noise exposure category } \\
\hline & 1 & 2 & 3 & 4 \\
\hline Traffic noise level (dB(A)) & $51-55$ & $56-60$ & $61-65$ & $66-70$ \\
\hline \multirow{6}{*}{$\begin{array}{l}\text { Traffic noise level } \\
\text {-PD } \\
+ \text { PD } \\
\text { Adjusted traffic noise level* } \\
\text {-PD } \\
\text { +PD }\end{array}$} & 1.00 & $0.71(0.46$ to 1.11$)$ & 0.68 (0.44 to 1.03$)$ & $1.07(0.70$ to 1.65$)$ \\
\hline & 1.00 & $0.78(0.42$ to 1.47$)$ & $0.97(0.55$ to 1.72$)$ & $1.03(0.55$ to 1.94$)$ \\
\hline & 1.00 & 0.65 (0.35 to 1.23 ) & $0.44(0.23$ to 0.84$)$ & $1.08(0.60$ to 1.95$)$ \\
\hline & 1.00 & $0.69(0.42$ to 1.12$)$ & $0.64(0.37$ to 1.09$)$ & 1.31 (0.78 to 2.21$)$ \\
\hline & 1.00 & 0.71 (0.35 to 1.43 ) & $0.89(0.44$ to 1.80$)$ & 0.84 (0.36 to 1.99$)$ \\
\hline & 1.00 & 0.70 (0.35 to 1.38$)$ & $0.43(0.18$ to 1.00$)$ & 1.82 (0.92 to 3.58 ) \\
\hline Annoyance/disturbances & Never & Seldom & Sometimes & Often + always \\
\hline \multirow{3}{*}{$\begin{array}{c}\text { Annoyance } \\
\text {-PD } \\
+P D\end{array}$} & 1.00 & $0.79(0.58$ to 1.08$)$ & $0.93(0.68$ to 1.27$)$ & 0.95 (0.52 to 1.75 ) \\
\hline & 1.00 & $0.70(0.44$ to 1.12$)$ & 1.05 (0.67 to 1.65 ) & 2.45 (1.13 to 5.31$)$ \\
\hline & 1.00 & 0.85 (0.56 to 1.28$)$ & 0.80 (0.52 to 1.23$)$ & $0.43(0.16$ to 1.13$)$ \\
\hline Concentration & 1.00 & $1.03(0.77$ to 1.36$)$ & $0.86(0.62$ to 1.20$)$ & 0.94 (0.50 to 1.74$)$ \\
\hline$-P D$ & 1.00 & $1.21(0.81$ to 1.81$)$ & 0.95 (0.57 to 1.56$)$ & $1.91(0.77$ to 4.74$)$ \\
\hline \multirow{2}{*}{$\begin{array}{l}+ \text { PD } \\
\text { Conversation, radio, TV }\end{array}$} & 1.00 & $0.86(0.58$ to 1.29$)$ & 0.78 (0.50 to 1.22 ) & $0.62(0.23$ to 1.44$)$ \\
\hline & 1.00 & $0.96(0.72$ to 1.29$)$ & 0.91 (0.64 to 1.29$)$ & $1.23(0.69$ to 2.18$)$ \\
\hline $\begin{array}{l}\text { Conversation, radio, TV } \\
\text {-PD }\end{array}$ & 1.00 & $1.23(0.82$ to 1.86$)$ & 0.78 (0.44 to 1.38$)$ & $2.17(1.00$ to 4.70$)$ \\
\hline \multirow{2}{*}{$\begin{array}{l}\text { PD } \\
\text { Relaxation }\end{array}$} & 1.00 & 0.75 (0.49 to 1.15 ) & $0.97(0.62$ to 1.51$)$ & 0.75 (0.32 to 1.75$)$ \\
\hline & 1.00 & 0.86 (0.64 to 1.16$)$ & 0.89 (0.62 to 1.27 ) & 1.39 (0.76 to 2.54$)$ \\
\hline $\begin{array}{l}\text { Relaxation } \\
\text {-PD }\end{array}$ & 1.00 & 0.94 (0.62 to 1.44$)$ & 0.75 (0.41 to 1.36$)$ & 2.61 (1.14 to 6.01 ) \\
\hline$+P D$ & 1.00 & $0.77(0.51$ to 1.18$)$ & 1.00 (0.63 to 1.59$)$ & 0.86 (0.36 to 2.04 ) \\
\hline \multirow{2}{*}{ Nervous o } & 1.00 & $1.19(0.88$ to 1.60$)$ & $0.92(0.60$ to 1.40$)$ & $1.28(0.63$ to 2.62$)$ \\
\hline & 1.00 & 1.01 (0.63 to 1.61$)$ & 0.98 (0.53 to 1.82 ) & 3.00 (1.12 to 8.02$)$ \\
\hline $\begin{array}{l}-\mathrm{PD} \\
+\mathrm{PD}\end{array}$ & 1.00 & $1.29(0.87$ to 1.91$)$ & 0.86 (0.48 to 1.54$)$ & $0.77(0.28$ to 2.14$)$ \\
\hline Falling asleep & 1.00 & $1.07(0.42$ to 1.76$)$ & 1.09 (0.76 to 1.57$)$ & $0.86(0.42$ to 1.76$)$ \\
\hline \multirow{2}{*}{$\begin{array}{l}-P D \\
+P D\end{array}$} & 1.00 & $1.02(0.65$ to 1.60$)$ & 0.76 (0.40 to 1.42 ) & $1.70(0.70$ to 4.17$)$ \\
\hline & 1.00 & $1.11(0.72$ to 1.71$)$ & $1.34(0.85$ to 2.11$)$ & 0.44 (0.13 to 1.45$)$ \\
\hline \multirow{2}{*}{ Waking up } & 1.00 & $1.10(0.82$ to 1.47$)$ & 1.01 (0.74 to 1.39$)$ & $1.38(0.79$ to 2.40$)$ \\
\hline & 1.00 & $1.42(0.94$ to 2.15$)$ & $1.15(0.71$ to 1.86$)$ & 2.06 (0.93 to 4.56$)$ \\
\hline$-P D$ & 1.00 & 0.83 (0.54 to 1.27$)$ & $0.92(0.60$ to 1.40$)$ & 1.05 (0.49 to 2.24 ) \\
\hline \multicolumn{5}{|c|}{$\begin{array}{l}\text { Results are given for the total sample }(n=3950) \text { and the stratified subsamples of subjects with }(n=1519) \text { and } \\
\text { without }(n=2431) \text { pre-existing diseases }(P D) \text {. } \\
+P D,-P D \text { : subjects with and without pre-existing disease. } \\
+{ }^{*} \text { Adjusted for room orientation and window opening habits. }\end{array}$} \\
\hline
\end{tabular}

disturbances with increasing sound level were only seen in subjects with pre-existing disease and not in healthy subjects. The percentages of highly disturbed subjects were independent of the sound level in men without pre-existing disease (table 4). On the other hand, annoyance (not disturbance) due to traffic noise showed the usual trend of an increase with increasing sound level in both subgroups. ${ }^{155}$ This suggests that noise disturbance and noise annoyance refer to different dimensions of reported noise stress in this study. The global item of noise annoyance comprises attributes of nuisance and disturbance..$^{4156}$

With regard to IHD incidence, the healthy subjects' abilities of coping with the physical noise stress may be more effective. No increase in IHD risk was found in men with no pre-existing disease with increasing sound level (table 5). On the other hand, men with pre-existing disease were more often affected by traffic noise when considering disturbed activities (table 4), and showed a slight, but non-significant tendency towards a higher IHD risk with increasing sound level (table 5). Contrary to expectation regarding the subjective perception of the noise, these men were not at higher risk. On the other hand, there was a strong increase in IHD risk in men without pre-existing disease with increasing annoyance/disturbance ratings.

The high response rates obtained in all phases of the study and the comprehensive assessment of IHD occurrence during the follow up, using all sources of information raise little concern about possible selection bias. However, recall bias could be an explanation of the interaction phenomenon. ${ }^{57}$ IHD incidence, IHD prevalence, and the pre-existing health condition were assessed on the basis of clinical measurements and standardised interviews by physicians who knew nothing about the noise exposure of the study subjects. The noise interview was made after the clinical interviews. This means that diagnostic bias and over-reporting of disease history because of the noise was not a problem in the study ${ }^{58}{ }^{59}$ However, due to the presence of a chronic disease, over-reporting of exposure (annoyance/disturbance) could be the case. Subjects with manifest health problems may be more likely to give exaggerated answers about their annoyance/disturbance by traffic noise in the interview although not virtually being stressed by the noise. They may tend to blame their environment for their health difficulties, hoping that the result of the study might influence future noise policy. ${ }^{60-62}$ Subjects who believe that the noise contributes to the health problem may be more dissatisfied and annoyed with noise. ${ }^{47}$ 63 In such cases, subjects who gave high annoyance ratings may have shown weaker physiological reactions than those with the same annoyance ratings who did not give such distorted answers. This dilutes the statistical noise effect. However, it may also be possible that some subjects played down the noise because they thought that it was of minor importance compared with their health problem, although they may have perceived the noise as a physiological stressor. Particularly with regard to sleep disturbances it has been shown that habituation does not take place when physiological reactions are considered. ${ }^{64}$ In such cases, subjects who gave low annoyance ratings may have shown higher physiological reactions than those with the same annoyance ratings who did not give such distorted answers. This again dilutes the statistical noise effect. All in all, these are sources of exposure misclassification that 
could lead to an underestimation of the true effect of the noise disturbance/annoyance on IHD incidence in the total sample.

Consequently, in the subsample free of pre-existing diseases where this source of exposure misclassification was not present, the subjects that were highly annoyed/disturbed by traffic noise had a markedly and sometimes a significantly higher risk of IHD incidence, depending on the item used. It should be noted that these results refer to prospective findings obtained from subjects who developed IHD during follow up. All noise measurements and interviews were taken before the follow up.

Two conclusions can be drawn from the study: Firstly, noise annoyance/disturbance is associated with IHD incidence (shown in men without pre-existing disease) and may be a risk factor. Secondly, annoyance/disturbance ratings from subjects with health problems (men with pre-existing disease) may be influenced by other factors, and must be viewed with caution with regard to recall bias. Prevalence of a disease is an important effect modifier in the relation between noise and cardiovascular health outcome in epidemiological studies. Recall bias, in particular, may be an issue when exposure and/or outcome are assessed on a subjective basis.

In social surveys, approximately $40-66 \%$ of the variation of community reaction to noise has been explained by the sound level and other known factors. ${ }^{65}$ Non-physical characteristics of the noise source are of great importance in the perception of noise annoyance. ${ }^{6}$ From the present study it can be seen that the prevalence of diseases may be a factor to be considered in social surveys and epidemiological studies, to improve the prediction of community responses to noise and to assess health effects of chronic noise stress. Noise annoyance is a subjective indicator of exposure that may be subject to recall bias for the reasons discussed. The subjective assessments of exposure may cause problems in observational studies. The interaction phenomenon was not much an issue when objective indicators of exposure were used. Certainly, there may be other effect modifiers to be considered. The focus here was on one which we thought would be of particular importance.

\section{Authors' affiliations}

W Babisch, $\mathbf{H}$ Ising, Federal Environmental Agency, Division of Environment and Health, Berlin, Germany

J E J Gallacher, MRC Epidemiology Unit (South Wales), Llandough Hospital, Penarth, UK

\section{REFERENCES}

1 Miedema HME, Vos H. Exposure-response relationships for transportation noise. J Acoust Soc Am 1998; 104:3432-45.

2 Schwela DH. The World Health Organization guidelines for environmental health. Noise/News International 2000 March:9-22.

3 Suter AH. Noise sources and effects-a new look. Sound and Vibration 1992;25th anniversary issue, 18-38.

4 Passchier-Vermeer W, Passchier WF. Noise exposure and public health. Environ Health Perspect 2000;108(suppl 1):123-31.

5 Borg E. Physiological and pathogenic effects of sound. Acta Otolaryngol 1981;(suppl 381):3-67.

6 Kjellberg A. Subjective, behavioral and psychophysiological effects of noise. Scand J Work Environ Health 1990;16(suppl 1):29-38.

7 Berglund B, Lindvall T. Community noise Document prepared for the World Health Organization. Stockholm: Center for Sensory Research, 1995

8 Henry JP, Stephens PM. Stress, health, and the social environment, a sociobiologic approach to medicine. New York: Springer-Verlag, 1977.

9 Ising H, Dienel D, Günther T, et al. Health effects of traffic noise. Int Arch Occup Environ Health 1980;47:179-90.

10 Lercher P. Environmental noise and health: an integrated research perspective. Environment International 1996;22:117-28.

11 Lehmann G, Tamm J. Über Veränderungen der Kreislaufdynamik des ruhenden Menschen unter Einwirkung von Geräuschen. Intern $Z$ angew Physiol einschl Arbeitsphysiol 1956;16:217-27.
12 Anticaglia JR, Cohen A. Extra-auditory effects of noise as a health hazard. American Industrial Hygiene Association Journal 1970;31:277-81.

13 Andrén L, Hansson L, Biörkman M, et al. Noise as a contributory factor in the development of elevated arterial pressure. Acta Med Scand 1980;207:493-8.

14 Manninen O, Aro S. Urinary catecholamines, blood pressure, serum cholesterol and blood glucose response to industrial noise exposure. Arh Hig Rada Toksikol 1979;30:713-18.

15 Ortiz GA, Argüelles AE, Crespin HA, et al. Modifications of epinephrine, norepinephrine, blood lipid fractions and the cardiovascular system produced by noise in an industrial medium. Hormone Res 1974;5:57-64.

16 Maschke C, Rupp T, Hecht K. The influence of stressors on biochemical reactions - a review of present scientific findings with noise. Int J Hyg Environ Health 2000;203:45-53.

17 Mosskov JI, Ettema JH IV. Extra-auditory effects in long-term exposure to aircraft and traffic noise. Int Arch Occup Environ Health 1977;40:177-84.

18 Frankenhaeuser $M$, Lundberg $U$. The influence of cognitive set on performance and arousal under different noise loads. Motivation and Emotion 1977; 1:139-49.

19 DiNisi J, Muzet A, Ehrhart J, et al. Comparison of cardiovascular responses to noise during waking and sleeping in humans. Association of Professional Sleep Societies 1990;13:108-20.

20 Jong RGd. Extraaural health effects of aircraft noise, a review. In: Ising H, Kruppa B (eds). Lärm und Krankheit [Noise and disease], Proceedings of the International Symposium, Berlin 1991. Stuttgart: Gustav Fischer Verlag, 1993:259-70

21 Friedman M, Rosenman RH. Der A-Typ und der B-Typ. Reinbek bei Hamburg: Rowohlt Verlag Gmbh, 1975.

22 Cohen S, Kessler RC, Underwood GL. Strategies for measuring stress in studies of psychiatric and physical disorders. In: Cohen S, Kessler RC, Underwood GL, eds. A guide for health and social scientists. New York: Underwood GL, eds. A guide for heath

23 Lundberg $U$. Coping with stress: neuroendocrine reactions and implications for health. Noise \& Health 1999:4:67-74.

24 Cantrell RW. Physiological effects of noise. Otolaryngologic Clinics of North America 1979; 12:537-49.

25 Hattis D, Richardson B. Noise, general stress responses, and cardiovascular disease processes: review and reassessment of hypothesized relationships, EPA Report 550/9-80-101. Washington, DC: United States Environmental Protection Agency, 1980.

26 WHO. Guidelines for community noise. Geneva: World Health Organization, 2000

27 Babisch W. Traffic noise and cardiovascular disease: epidemiological review and synthesis. Noise \& Health 2000;2(8):9-32.

28 Babisch W. Epidemiological studies of the cardiovascular effects of occupational noise-a critical appraisal. Noise \& Health 1998;1(1):24-39.

29 Babisch W. The noise/stress concept, risk assessment and research needs. Noise \& Health 2002;4(16):1-11.

30 Gallacher JEJ, Elwood PC, Hopkinson C, et al. Cognitive function in the Caerphilly study: associations with age, social class, education and mood. Eur J Epidemiol 1999;15:161-9.

31 Yarnell JWG, Sweetnam PM, Baker IA, et al. Diagnosis of past history of myocardial infarction in epidemiological studies: an alternative based on the Caerphilly and Speedwell surveys. J Epidemiol Community Health 1988:42:116-20.

32 Yarnell JWG, Baker IA, Sweetnam PM, et al. Fibrinogen, viscosity, and white blood cell count are major risk factors for ischemic heart disease: the Carephilly and Speedwell collaborative heart disease studies. Circulation 1991:83:836-44.

33 Bainton $\mathrm{D}$, Miller NE, Bolton $\mathrm{CH}$, et al. Plasma triglyceride and high density lipoprotein cholesterol as predictors of ischaemic heart disease in British men; The Caerphilly and Speedwell Collaborative Heart Disease Studies. Br Heart $J$ 1992:68:60-6.

34 Bainton D, Baker IA, Sweetnam PM, et al. Prevalence of ischaemic heart disease: the Caerphilly and Speedwell surveys. Br Heart J 1988;59:201-6.

35 Fallon UB, Elwwod P, Ben-Shlomo Y, et al. Homocysteine and ischaemic stroke in men: the Caerphilly study. J Epidemiol Community Health 2001;55:91-6.

36 Stansfeld S, Gallacher J, Babisch W, et al. Road traffic noise and psychiatric disorder: prospective findings from the Caerphilly study. BMJ 1996;313:266-7

37 Babisch W Ising $\mathrm{H}$, Gallacher JEJ et al. Traffic noise and cardiovascular risk: the Caerphilly and Speedwell studies, third phase-10 years follow-up. Arch Environ Health 1999;54:210-16.

38 Babisch W, Fromme H, Beyer A, et al. Increased catecholamine levels in urine in subjects exposed to road traffic noise. The role of stress hormones in noise research. Environment International 2001:26:475-81.

39 MRC Epidemiology Unit Cardiff. The Caerphilly collaborative heart disease studies. Project description and manual of operations. Cardiff: MRC Epidemiology Unit (South Wales), 1985.

40 Guski R, Felscher-Suhr U, Schuemer R. The concept of noise annoyance: how international experts see it. Journal of Sound and Vibration 1999;223:513-27.

41 Guski R. About the validity of global annoyance judgements. In: Boone R, ed. Internoise 2001, Proceedings of the 2001 International Congress and Exhibition on Noise Control Engineering, The Hague. Maastricht: Nederlands Akoestisch Genootschap, 2001:1663-6.

42 Fields JM, De Jong RG, Gjestland T, et al. Standardized general-purpose noise reaction questions for community noise surveys: research and recommendation. Journal of Sound and Vibration 2001:242:641-79. 
43 Sweetnam PM, Thomas HF, Yarnell JWG, et al. Fibrinogen, viscosity and the 10-year incidence of ischaemic heart disease; The Caerphilly and Speedwell Studies. Eur Heart J 1996;17:1814-20.

44 Gierke HEv, Eldred KM. Effects of noise on people. Noise/News International 1993:6:67-89.

45 Thompson S. Non-auditory health effects of noise: updated review. In: Hill FA, Lawence R, eds. InterNoise 96, Proceedings of the 25th International Congress on Noise Control Energineering, Liverpool, 1996. St Albans: Institute of Acoustics, 1996:2177-82.

46 Babisch W, Ising $\mathrm{H}$. Noise induced stress is a risk factor in cardiovascular disease. In: Boone R, ed. Internoise 2001, Proceedings of the 2001 International Congress and Exhibition on Noise Control Engineering, The Hague. Maastricht: Nederlands Akoestisch Genootschap, 2001:1703-12.

47 Job RFS. The influence of subjective reactions to noise on health effects of the noise. Environment International 1996;22:93-104.

48 Cott CA, Gignac MAM, Badley EM. Determinants of self rated health for Canadians with chronic disease and disability. J Epidemiol Community Health 1999;53:731-6.

49 Manderbacka K, Lahelma E, Martikainen P. Examining the continuity of selfrated health. Int J Epidemiol 1998;27:208-13.

50 Winkleby MA, Ragland DR, Syme SL. Self-reported stressors and hypertension: evidence of an inverse association. Am J Epidemio 1988; 127:124-33.

51 Brown AL, Hall A, Kyle-Little J. Response to a reduction in traffic noise exposure. Journal of Sound and Vibration 1985;98:235-46.

52 Brown AL. Responses to an increase in road traffic noise. Journal of Sound and Vibration 1987;117:69-79.

53 Jansen G. Effects of traffic noise on critical groups (in German). Zeitschrift für Lärmbekämpfung 1987;34:152-6.

54 Porter ND, Flindell IH, Berry BF. Health effect-based noise assessment methods: a review and feasibility study. Teddington: National Physical Laboratory, 1998.

55 Miedema HME, Oudshoorn CGM. Annoyance from transportation noise: relationships with exposure metrics DNL and DENL and their confidence intervals. Environ Health Perspect 2001;109:409-16.
56 Guski R. Aspects contributing to global annoyance judgements in field interviews. In: Cassereau D, eds. Internoise 2000, The 29th International Congress and Exhibition on Noise Control Engineering, Vol. 5. Nice: Sociéte Francaise d'Acoustique (SFA), 2000:3220-3.

57 Hennekens $\mathrm{CH}$, Buring JE. Epidemiology in medicine. Bosten/Toronto: Little, Brown and Company, 1987.

58 Stansfeld S, Gallacher J, Babisch W, et al. Road traffic noise, noise sensitivity and psychiatric disorder: preliminary prospective findings from the Caerphilly Study. In: Vallet M, eds. Noise \& Man '93, Proceedings of the 6th International Congress on Noise as a Public Health Problem, Nice, 1993. Arcueil Cedex: Institut National De Recherche Sur Les Transports Et Leur Sécurité, 1993:268-73.

59 Malmström M, Sundquist J, Johansson S-E. Neighborhood environment and self-reported health status: a multilevel analysis. Am J Public Health 1999;89:1181-6.

60 Cartwright J, Flindell I. Research methodology - noise annoyance and health In: Cassereau D, eds. Internoise 2000, Proceedings of the 29th International Congress on Noise Control Engineering, Nice. Nice: Société Française d'Acoustique (SFA), 2000:2116-20.

61 Job RFS. Over-reaction to changes in noise exposure: the possible effect of attitude. Journal of Sound and Vibration 1988;126:550-2.

62 Lercher $\mathbf{P}$, Widmann U. Factors determining community response to road traffic noise. In: Vallet M, eds. Noise and Man '93, Proceedings of the 6th International Congress on Noise as a Public Health Problem, Nice 1993. Arcueil Cedex: Institut National de Recherche sur les Transports et leur Sécurité, 1993:201-4.

63 Hatfield J, Job RFS, Carter NL, et al. The influence of psychological factors on self-reported physiological effects of noise. Noise \& Health 2001;3(10): 1-13.

64 Andersson K, Lindvall T. Health effects of community noise; evaluation of the Nordic project on "the health effects of community noise", Copenhagen, 1988.

65 Job SRF. Psychological factors of community reaction to noise. In: Vallet $M$, ed. Noise \& Man'93. Nice: INRETS, 1993:48-59.

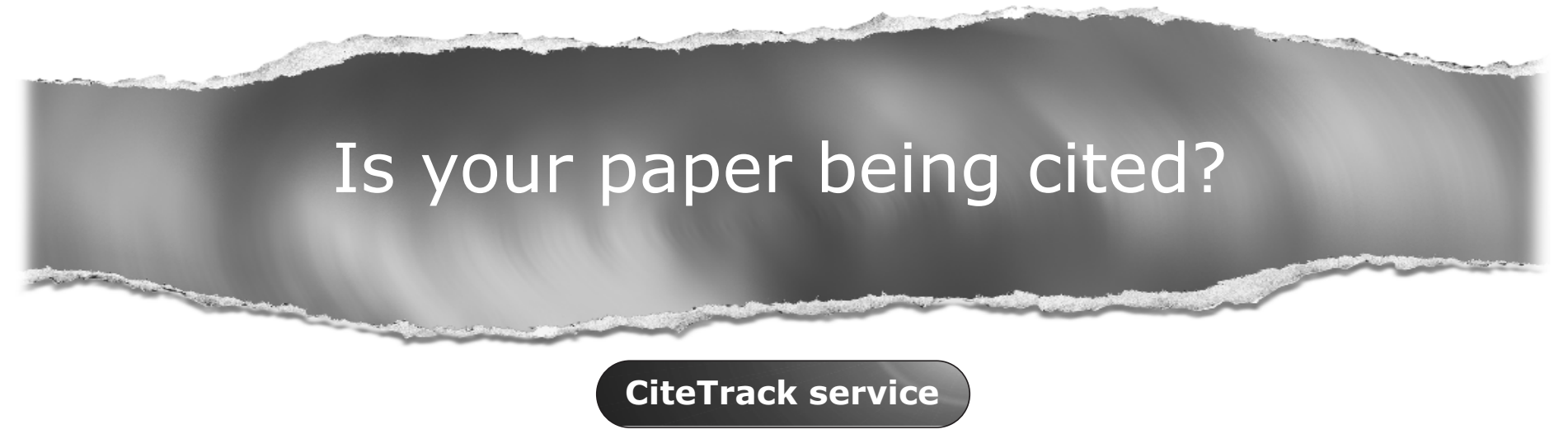

CiteTrack will alert you by email whenever new content in Occupational and Environmental Medicine or a participating journal is published that matches criteria you want to track

Topics: Tell CiteTrack which words or subjects to watch for in new content Authors: Be alerted whenever key authors you are following publish a new paper Articles: Know whenever a paper of interest to you is referenced by another paper

\section{www.occenvmed.com}

